Publicación del Seminario "Ángel González Álvarez" de la Fundación Universitaria Española

Número monográfico sobre Mujer y cambio social Año 2021

\title{
En el corazón de la economía, el genio femenino
}

\author{
At the heart of the economy, the female genius
}

\author{
Ma Peana Chivite-Cebolla \\ Universidad Católica de Ávila. España \\ ID ORCID 0000-0003-4774-6259 \\ mpeana.chivite@ucavila.es
}

JAVIER JORGE-VÁZQUEZ

Universidad Católica de Ávila

ID ORCID 0000-0003-3654-7203

javier.jorge@ucavila.es

Recibido: 21-07-2021 | Revisado: 17-09-2021

Aceptado: 20-09-2021 | Publicado: 30/12/2021

DOI: https://doi.org/10.51743/cpe. 214

RESUMEN: El tema de la mujer ha sido objeto de estudio desde muchas perspectivas, pero en este trabajo se propone estudiar el papel de la mujer desde dos. Por un lado, se revisará su influjo a nivel general en la economía, como estudiante, investigadora o profesional en esta rama, y por otro, particularmente en la economía familiar. Así mientras en el primero se encontrará un sesgo a favor del hombre en el segundo será a favor de la mujer.

PALABRAS ClAVE: Mujer y sociedad, familia, economía del hogar, mujer y economía. 
ABSTRACT: The subject of women has been the object of study from many perspectives, but in this work it is proposed to study the role of women from two perspectives. On the one hand, the influence of it at a general level in the economy will be reviewed, as a student, researcher or professional in this branch, and on the other, particularly in the family economy. Thus, while in the first there will be a bias in favor of the man, in the second it will be in favor of the woman.

KEYWORDS: Women and society, family, home economics, women and economy.

\section{INTRODUCCIÓN}

os encontramos en una sociedad en continuo cambio, $\mathrm{y}$, si hablamos de
los tres grandes bloques en los que se podría dividir, a saber, estado, empresas (organizaciones) y familias, quizás estas últimas sean las más afectadas. Ciertamente factores como la incorporación de la mujer al mercado laboral han supuesto un cambio importante que ha influido en la familia y en la sociedad en su conjunto. Pero, si bien es cierto que esta perspectiva es tenida en cuenta en factores como el Producto Interior Bruto (PIB) o en factores asociados a la igualdad, se tiende a obviar otros factores, como puede ser la pérdida que implica un cambio de actividad. Toda elección supone una renuncia a aquello que se deja de hacer por lo que se elige como alternativa, en este caso el cuidado del hogar por el trabajo fuera de este. Las mujeres siempre han trabajado, aunque su trabajo no haya sido "remunerado", la cuestión es ¿qué implicaciones pueden tener este cambio?

$\mathrm{Si}$ acudimos a los estudios realizados sobre el papel de la mujer en la sociedad, estos se centran en analizar cuáles son los puestos de trabajo que desempeñan dentro de las empresas, su remuneración, su formación, etc., sin apenas considerar la repercusión económica y social a largo plazo que ciertos cambios pueden tener. Se preguntan por el volumen de mujeres en puestos directivos, pero no por la tasa de renuncia a dichos puestos por mujeres que prefieren priorizar otros aspectos de su vida. Los estudios muestran una preocupación por la incorporación de la mujer al trabajo, pero no por qué es lo que ella prefiere, cuál es su capacidad de elección, o qué es a lo que está renunciando. Quizás en parte de estos enfoques haya un reflejo del espíritu parcial y totalitario del feminismo 
revelado por Simone de Beauvoir, que le dijo a Betty Friedan: "No se le debería autorizar a ninguna mujer quedarse en casa para criar a sus hijos... Las mujeres no deberían tener esa elección, precisamente porque si existe esa opción muchas mujeres la cogerán" (Citado por Christina Hoff Sommers, Who Stole Feminism? (New York: Simon and Schuster, 1994), p. 256).

Ciertamente el tema de la mujer ha sido objeto de estudio desde muchas perspectivas, pero en este trabajo se propone estudiar el papel de la mujer desde dos. Por un lado, se revisará su influjo a nivel general en la economía, como estudiante, investigadora o profesional en esta rama y, por otro particularmente en la economía familiar. Así mientras en el primero se encontrará un sesgo a favor del hombre, en el segundo será a favor de la mujer.

Para comprobar la posición de la mujer en el mundo de la economía, desde una perspectiva más académica, se revisarán principalmente investigaciones y estadísticas ya publicadas. Para abordar el papel de la mujer en la economía familiar se analizarán no solo estadísticas y publicaciones, sino que se completará con un estudio empírico.

Lo más significativo del trabajo se recogerá en el segundo apartado, dónde se quiere valorar si la gestión de los recursos económicos en las familias ha estado en manos de las mujeres o de los hombres. Para ello se ha realizado una encuesta a 140 personas, de edades comprendidas entre los 18 y los 81 años, lo que permite revisar varias generaciones. A todos ellos se les ha preguntado sobre los distintos roles asumidos en sus familias.

Los resultados señalan cómo la mujer ha tenido un papel clave en la economía familiar, viéndose reducido en las generaciones actuales y apareciendo los abuelos como nuevos exponentes. Entre las conclusiones que se plantean, resalta el hecho de que estos cambios han podido tener consecuencias negativas en la relación o influencia que el padre ejerce sobre los hijos.

\section{LA MUJER EN EL MUNDO DE LA ECONOMÍA}

\subsection{Mujer e investigación en la economía}

En la actualidad, y a pesar de los avances observados en los últimos años, aún existen muchos ámbitos de la sociedad en los que la mujer se encuentra 
subrepresentada. Sin duda, la investigación científica constituye un ejemplo de ello.

Basta analizar la proporción de investigadoras en Europa para observar la existencia de un diferencial significativo respecto de los hombres. Solamente Macedonia del Norte y Letonia presentan una presencia mayor de mujeres en el campo de la investigación. En España, el porcentaje de investigadores sobre el total se eleva al $38,8 \%$, mientras que en países como Alemania, Chequia, Austria o Francia no supera un tercio del total (véase figura 1).

\section{Figura 1. Propor- ción de investiga- doras (EJC)*. EU (27), 2017. (\% del total de investigadores)}

$\left(^{*}\right)$ EJC: equivalencia a jornada completa Fuente: Eurostat.

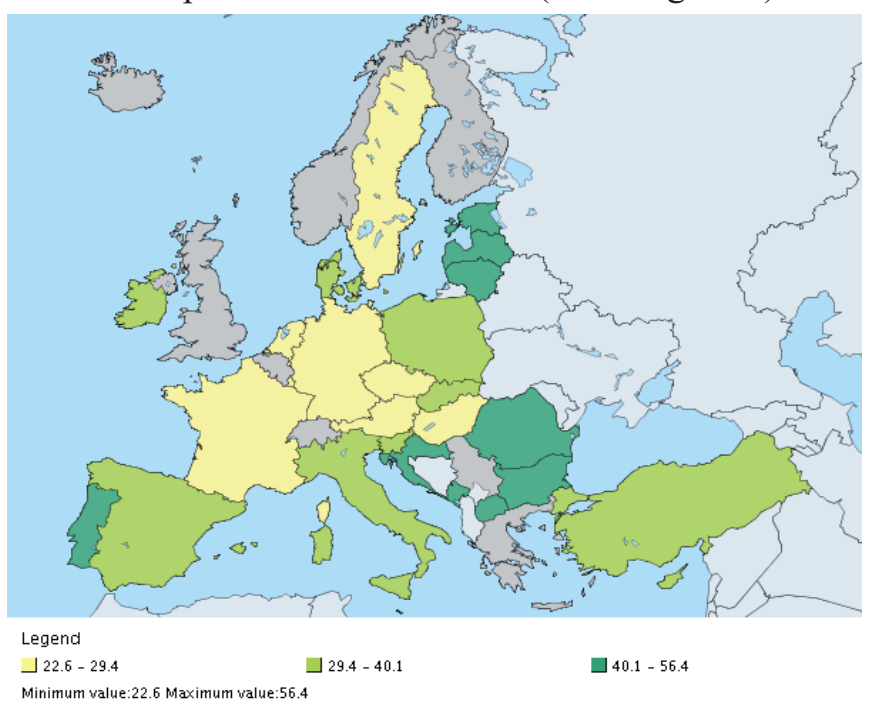

En las últimas décadas el estudio del papel que desempeña la mujer en el ámbito de la investigación y su relación con la ciencia ha sido objeto de gran interés por parte de la comunidad científica. Los estudios publicados en este ámbito se cuantifican en numerosos. Igualmente, desde el punto de vista institucional, han sido varias las iniciativas y recomendaciones propuestas por las instituciones comunitarias, como la Comisión Europea (CE) o el Parlamento Europeo (PE), que han puesto de manifiesto la necesidad de impulsar actuaciones que promuevan la mejora de la presencia de la mujer en todos los ámbitos del Sistema Español de Ciencia y Tecnología ${ }^{1}$.

\footnotetext{
${ }^{1}$ En este contexto, con la finalidad de conocer la situación e impulsar la presencia de la mujer y su participación en la investigación, en el Sistema Español de Ciencia y
} 
En España, la presencia de la mujer y su participación en la investigación mejoró sensiblemente en la primera década del s.XXI, si bien a partir del año 2010 se observa un claro estancamiento, manteniéndose el predominio mayoritario de los hombres en el ámbito de la investigación (véase figura 2).

\section{Figura 2. Investigadores según sexo. España (2001-2017)}

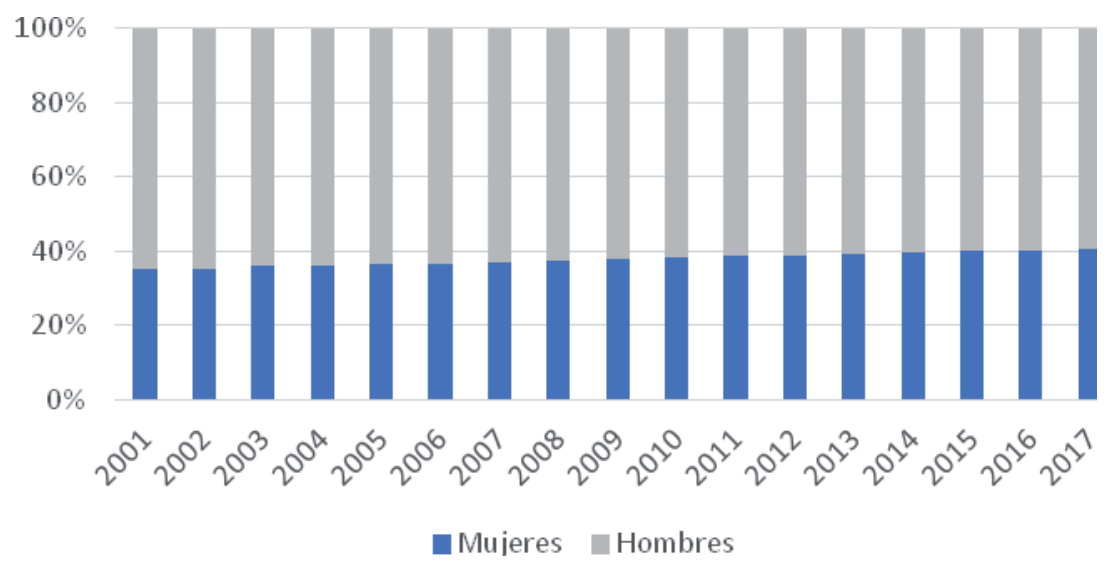

Fuente: Elaboración propia a partir de UNECE Statistical Division Database

Tabla 1. Mujeres investigadoras (en EJC)* por sectores de ejecución. España

(*) EJC: equivalencia a jornada completa

Fuente: Estadística sobre actividades de I+D. INE

Porcentaje (\%)

\begin{tabular}{|c|c|c|c|c|c|}
\hline & 2017 & 2016 & 2015 & 2014 & 2013 \\
\hline Total & $\mathbf{3 8 , 8}$ & 39,1 & 39,0 & 38,6 & 38,8 \\
\hline Empresas & 31,3 & 30,6 & 31,0 & 30,9 & 31,1 \\
\hline Enseñanza superior & 41,6 & 42,9 & 42,5 & 41,9 & 41,6 \\
\hline Administración Pública & 47,9 & 47,6 & 46,8 & 45,9 & 47,3 \\
\hline Instituciones privadas sin fines de lucro & 52,7 & 47,8 & 53,7 & 56,2 & 54,7 \\
\hline
\end{tabular}

Tecnología se creó en 2006 la unidad específica de "Mujeres y Ciencia". 
Un análisis de la situación de las mujeres investigadoras en España, atendiendo a la clasificación sectorial, permite concluir la existencia de una distribución heterogénea entre los distintos sectores. Así, las instituciones privadas sin ánimo de lucro emplean a una proporción mayor de mujeres que de hombres en el ámbito de la investigación. Por el contrario, en el resto de los sectores existe una evidente subrepresentación que se agudiza en el caso de las empresas. En el ámbito universitario y en las Administraciones Públicas dicha brecha entre hombres y mujeres se reduce, aunque no logra cerrarse, al observarse un claro estancamiento, cuando no regresión, a lo largo de los últimos cinco años de los que se disponen cifras (véase tabla 1)

Por otro lado, la participación de la mujer en los órganos colegiados de dirección y decisión en el ámbito de la ciencia aún queda lejos de reducir la brecha existente. Tal y como refleja la figura 3, en términos generales, la ocupación de puestos de decisión en las academias nacionales de ciencia presenta un claro sesgo masculino en la mayoría de los países europeos. Tan sólo en Bélgica y Noruega, se invierte esta situación (véase figura 3).

\section{Figura 3. Presencia de las mujeres en los máximos órganos de de- cisión de las academias nacionales de ciencia. 2019}

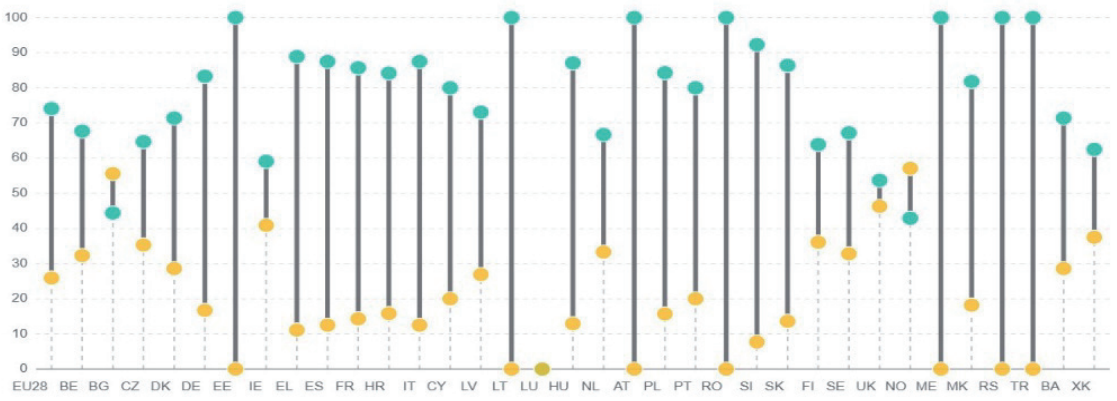

\section{Hombres Mujeres}

Fuente: European Institue for Gender Equality. Gender Statistics Database. 
El ámbito de la Ciencia Económica no es ajeno a esta situación, por el contrario, en la actualidad aún sigue persistiendo una presencia relativamente residual de las mujeres en este campo de conocimiento, tanto en el desempeño de puestos de responsabilidad en instituciones académicas como en el ámbito específico de la investigación y la producción científica. Según Calviño (2019) basta con analizar algunas cifras, para evidenciar un sesgo eminentemente masculino de esta disciplina académica de las Ciencias Sociales: "En Europa solo un 20\% de los economistas senior son mujeres, mientras que en EE.UU solo hay un $15 \%$ de catedráticas en economía [...] Y solo una mujer en la historia ha ganado el Premio Nobel de Economía" (p.7).

Una primera aproximación a los antecedentes de investigación sobre el estado de la cuestión revela que la existencia de esta subrepresentación de las mujeres en el campo de la economía ha sido objeto de gran interés por parte de la comunidad científica. En este contexto son numerosos los trabajos desarrollados (Ginther y Kahn, 2004; May, McGarvey y Whaples, 2013; Bayer y Rouse, 2016; Chari y Goldsmith-Pinkham, 2017, Beneito, Boscá, Ferri y García, 2018; Lundberg y Stearns, 2019; Auriol, Friebel, Wilhelm, 2019, entre otros, que analizan la situación de la mujer en la profesión económica y pretenden arrojar luz a este problema a través de la caracterización y cuantificación de dicha brecha, la identificación de los principales factores condicionantes y el análisis de las consecuencias derivadas de la falta de diversidad existente.

La evidencia empírica demuestra que en el área económica el avance en la reducción de la brecha entre hombres y mujeres es menor que en otras disciplinas científicas de las ciencias sociales, las humanidades e incluso de las áreas denominadas STEM (ciencia, tecnología, ingeniería y matemáticas) si comparamos el incremento en la proporción de mujeres que deciden cursar estudios superiores u obtienen un doctorado (Bayer y Rouse, 2016). Tal circunstancia, supone una barrera en la reducción del sesgo masculino en el campo de la investigación económica futura. Uno de los factores explicativos que a menudo se esgrimen para explicar la existencia de este diferencial, se centra en el menor interés que despierta en las mujeres el campo de la economía, atribuible, tal circunstancia, a posibles "diferencias exógenas de gustos entre los géneros" (Auriol et al., 2019:2). Otras explicaciones recurrentes señalan que ese menor atractivo por la economía se debe a la existencia de una menor preferencia de las 
mujeres por aquellas disciplinas con mayor contenido matemático o incluso a la presencia de un estereotipo marcado del economista como varón (Beneito et al, 2018).

En este contexto, algunos estudios recientes demuestran que la elección del campo de investigación condiciona en buena medida la existencia de la brecha entre hombres y mujeres en la producción de la investigación económica (Ductor, Goya y Prummer, 2018). Son varios los trabajos publicados (Boschini y Sjögren, 2007; May, et al. 2013; Chari y Goldsmith-Pinkham, 2017; entre otros) que evidencian la presencia de una representación significativamente menor de las mujeres en las áreas de investigación vinculadas con el campo de la macroeconomía, las finanzas, las matemáticas o los métodos cuantitativos, frente a otras áreas como la laboral o la microeconomía aplicada, donde su presencia es mucho más notable (véase figura 4).

\section{FIGURA 4. Temas de disertación de mujeres por año (1990-2017)} A: Women

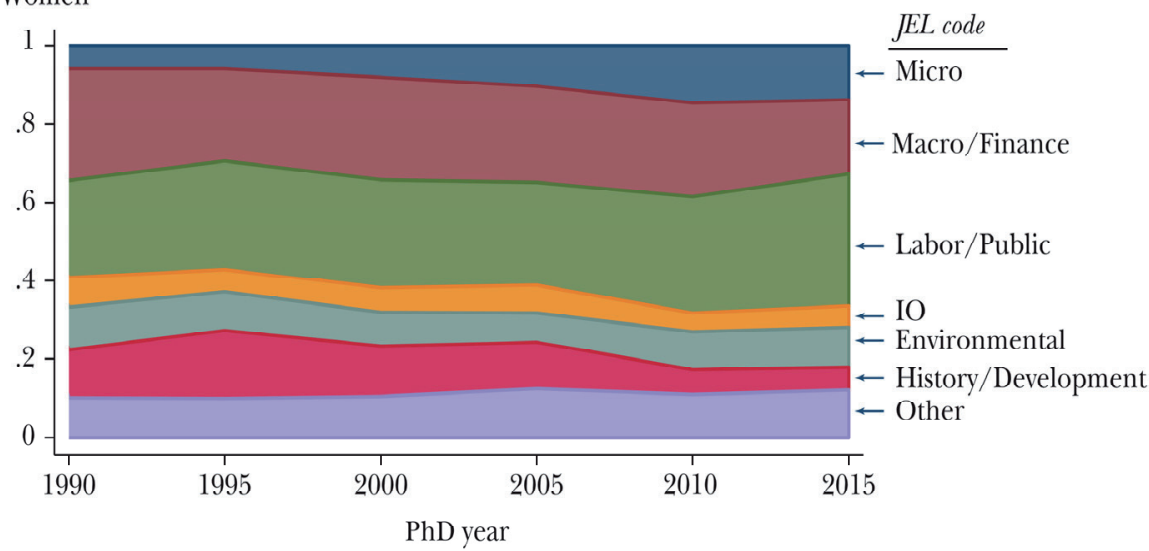

Fuente: Lundberg y Stearns (2019:11). Los autores han utilizado datos de la lista anual de tesis doctorales en economía, 1991-2017.

En esta misma línea, Beneito et al. (2018), a partir del análisis de las contribuciones presentadas en el congreso anual de la American Economic Association, observan cómo en el periodo trascurrido entre 2010 y 2016, el porcentaje de mujeres que investigan en el campo de la economía se sitúa 
estancado en un promedio del 24\%. Además, su distribución entre las distintas áreas de investigación refleja una preferencia marcada por la microeconomía (cerca del 30\%) frente a otras áreas como la macroeconomía, finanzas y econométrica (próximo al 18\%). Análogo resultado obtiene al evaluar los abstract presentados, donde el interés de las investigadoras economistas se concentra especialmente en temas específicos relacionados con la economía de la salud, la educación o la laboral.

Estos resultados pueden corroborarse al analizar la preferencia de las mujeres por otros campos de conocimientos cercanos al ámbito de la economía como son las finanzas, la gestión o el marketing, a través del porcentaje de estudiantes femeninas sobre el total de alumnos matriculados en las titulaciones oficiales de grado (véase figura 5).

\section{Figura 5. Estudiantes mujeres matriculadas en titulaciones de grado en el campo de conocimiento de las ciencias económicas. España (2018).}

Porcentaje de mujeres sobre el total (\%)

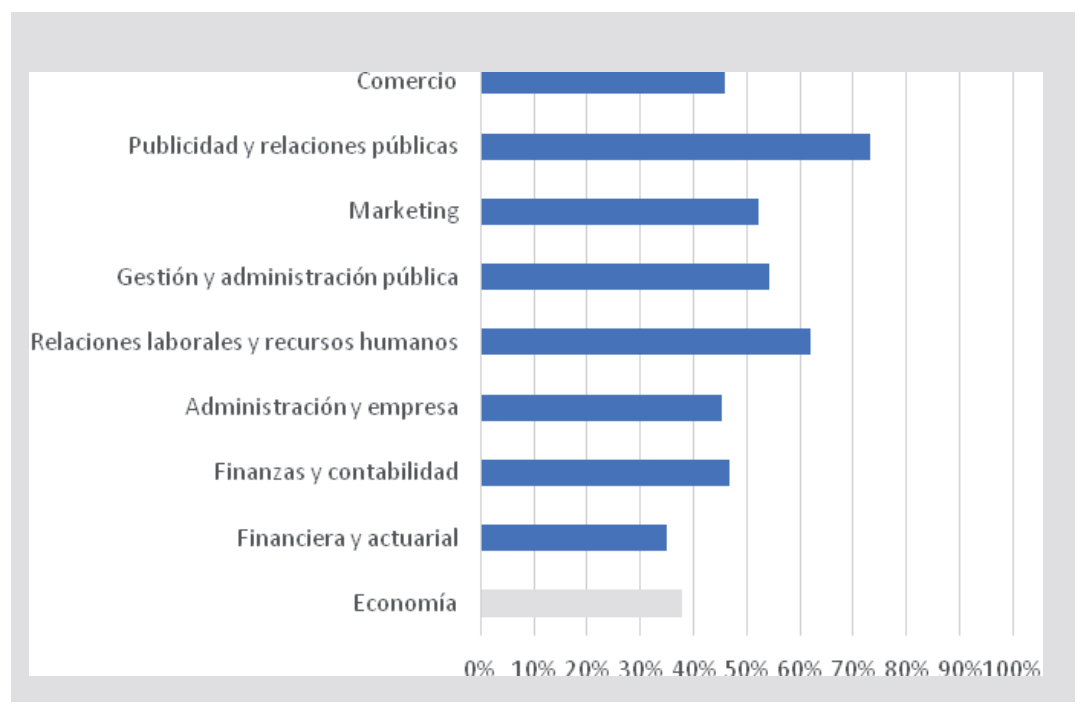

Fuente: Elaboración propia a partir del Ministerio de Educación y Formación Profesional / Ministerio de Ciencia, Innovación y Universidades 
En los últimos años y en términos generales, la presencia de las mujeres en la disciplina académica de economía se ha ralentizado. En España, si bien en el año 2013 poco más del 39\% de los estudiantes matriculados en programas de doctorado eran mujeres, al finalizar 2018 esa cifra se contraía al $36 \%$. Similar tendencia se observa en la evolución del número de alumnas matriculadas en titulaciones de Grado o equivalentes, con una participación media en los últimos años algo inferior al 38\% del total de alumnos (véase figura 6). Por el contrario, la única etapa educativa que se desmarca de esta tendencia, son las titulaciones de postgrado. En este ámbito académico, se observa una mayor presencia de mujeres, en particular, un $58,5 \%$ sobre el total de estudiantes, con un crecimiento medio a lo largo de los últimos cinco años (2013-2018) sensiblemente superior al 1\%.

\section{Figura 6. Alumnos matriculados en educación superior por nivel educativo en el campo de las ciencias económicas. España (2018) / (2015-2020)}

Porcentaje sobre el total de alumnos (\%)
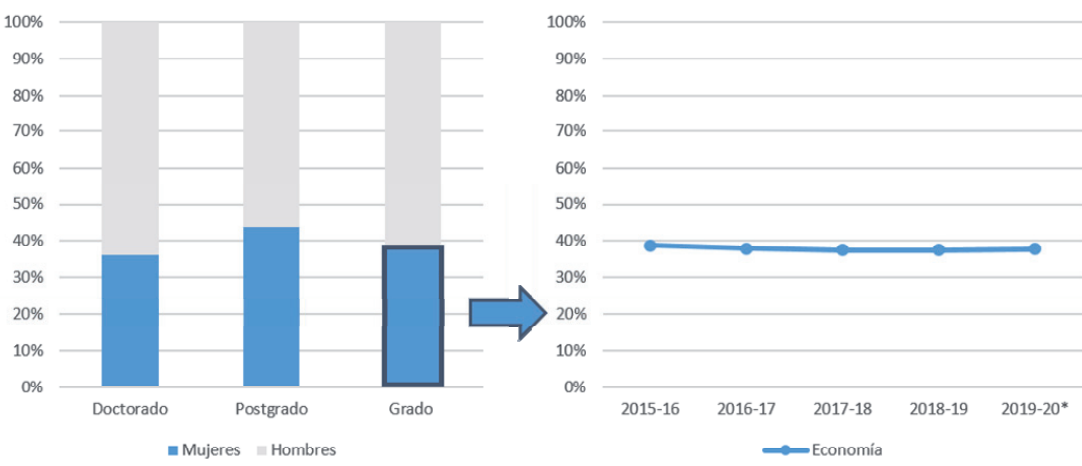

Fuente: Elaboración propia a partir de Eurostat data e INE.

La reducción de las diferencias en el ámbito docente es lenta, pero sigue una tendencia creciente. Si a principios de 2011 el porcentaje de mujeres catedráticas de universidad ascendía al 19,5\% del total, en 2018 dicha cifra representa un porcentaje del 22,5\%. Dicha brecha es menor, al considerar la figura de profesores titulares de universidad, donde el 40,8\% del total son mujeres, aunque a lo largo de los últimos años se observa un claro estancamiento. 
Esta tendencia se observa también en el campo de la economía. Así, el estudio publicado por Lundberg y Stearns (2019) concluye que "la representación de las mujeres en los departamentos de economía tiende a disminuir a medida que aumenta el rango académico ${ }^{2}$ " (p.17). Tal circunstancia es visible al analizar los datos procedentes del Cuestionario Académico Universal que elabora anualmente la Asociación Económica Americana y que revelan que tan solo el 23,5\% del personal docente e investigador de las facultades de economía con titularidad y en régimen de dedicación exclusiva son mujeres (Scott y Siegfried, 2016). Por su parte, Ginther y Khan (2014) concluyen que la brecha en la promoción del profesorado en el área de economía es casi el doble que en el resto de disciplinas de las ciencias sociales. Si bien tal circunstancia podría atribuirse a efectos del desfase existente entre la obtención del doctorado y la promoción a una figura académica de rango superior, el mantenimiento de dicha brecha a lo largo de los últimos años parece señalar que sea poco probable esta explicación. Por ello, algunos autores señalan la existencia de un efecto "leaky pipeline" (Corsi et al., 2014; Auriol, et al., 2019 entre otros), es decir, la representación de las mujeres en este ámbito sería inferior al que les correspondería atendiendo a su formación en condiciones normales.

\section{Figura 7. Mujeres en el profesorado de educación universitaria en las universidades públicas por categoría y curso. España (2017).}

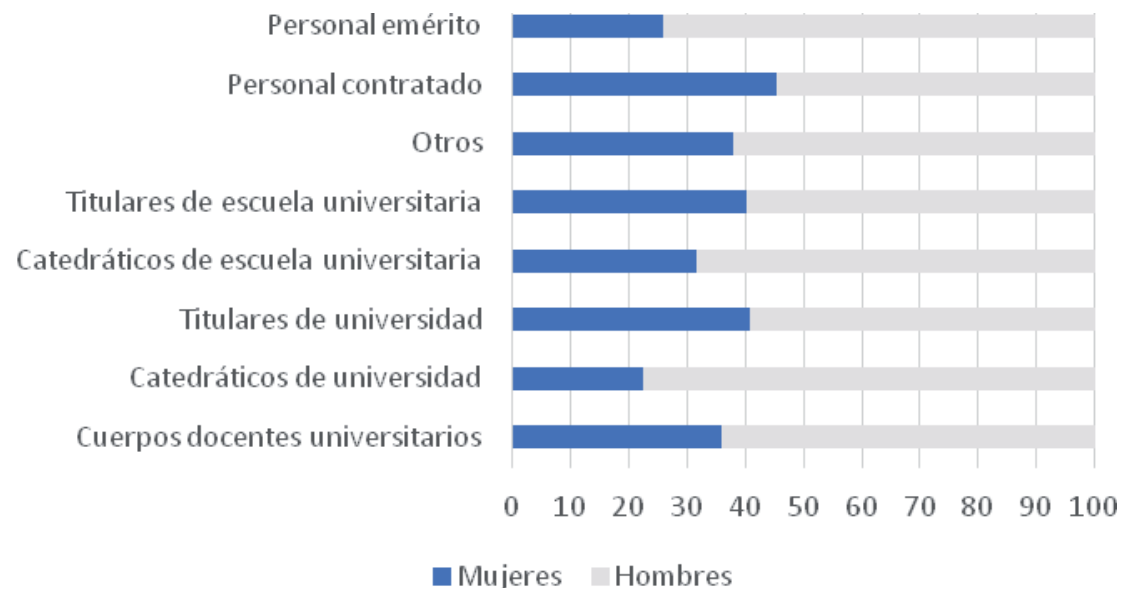

Fuente: Elaboración propia a partir de los datos del INE. 
En cuanto a la productividad científica, el estudio desarrollado por West, Jacquet, King, Correll y Bergstrom, (2013) identifica la existencia de una subrepresentación de las mujeres en cuanto a la autoría de las investigaciones académicas publicadas desde 1990 en el ámbito económico. En particular, tan sólo el 13,7\% de las publicaciones analizadas en esta disciplina corresponden a mujeres, un porcentaje muy inferior a la media general que se sitúa en torno al $27 \%$.

En definitiva, parece claro que la evidencia empírica disponible confirma la existencia de una brecha entre hombres y mujeres persistente hoy en día en el campo de la investigación académica en economía que, lejos de corregirse en los últimos años, parece haberse estancado. Del estudio desarrollado se concluye que tal circunstancia, se debe a la concurrencia en el tiempo de múltiples factores condicionantes, sin que exista una única explicación plausible al problema, por lo tanto, de gran interés como objeto de estudio de futuras investigaciones.

\subsection{La mujer clave de la economía familiar}

La mujer, al igual que el hombre, desempeña un papel clave en la familia, en la empresa y en el estado, donde cada uno aporta sus cualidades y capacidades para contribuir a crear una sociedad mejor. Es por ello importante no obviar que, dentro de la igualdad, somos distintos, con distintas capacidades y cualidades, gustos y preferencias. Es en esa diversidad y complementariedad dónde reside nuestra fuerza. Así, si se saben potenciar y desarrollar en cada persona, hombre y mujer con sus particularidades concretas, sus cualidades, se podrá contribuir de manera efectiva a la creación de una sociedad mejor.

Existen muchos trabajos preocupados por la situación de la mujer desde el punto de vista económico, su situación laboral y el papel que desempeña. Por ejemplo, si hablamos del mundo rural, encontramos trabajos que muestran el papel indispensable de la mujer, que contribuye a paliar la despoblación, y a generar renta y empleo. Así Rico y Gómez (2009) afirman que la participación de la mujer en la economía y sociedad, en concreto para las zonas rurales de Castilla y León, es una condición indispensable para alcanzar un mayor bienestar. 
Por otra parte, se detecta la preocupación por garantizar la incorporación del hombre y de la mujer al mercado laboral. Pero del mismo modo, existe la necesidad de idear políticas sociales que permitan una elección real tanto para el hombre como para la mujer respecto del trabajo remunerado y del no remunerado (poder encargarse del hogar) resultando estas medidas insuficientes. Este factor ha convertido, según señalan algunos autores (MestreMiquel et al, 2012) a las abuelas en un recurso clave para poder conciliar la vida laboral y familiar.

Porque cabe recordar que el trabajo no remunerado (hogar) es un trabajo importante. En el estudio "El trabajo no remunerado en la economía global" (Duran, 2012) se marca que dentro del PIB hay trabajos que no son considerados y que tienen un valor importante. Citando a Schneider y Klingimair, hablan de que en los países en vías de desarrollo la economía no incorporada supone un $41 \%$ del PIB, en los que proceden de antiguos regímenes socialistas el $38 \%$ y en los de la OCDE el 18\%. Es decir, que las cuentas nacionales no miden toda la economía, sino parte de ella. Señalan su preocupación al observar que parte de las estadísticas y de las investigaciones no se encaminan a medir la economía en su totalidad sino la que les interesa. Siendo, los servicios producidos por los miembros de los hogares parte de esa economía que no se contempla. Este trabajo cuestiona la baja estima que la sociedad da al papel de la gestión del hogar, y la necesidad de reconocerlo y valorarlo, dada su importancia.

A continuación, se muestran algunas estadísticas publicadas sobre la situación actual de la mujer, según el Instituto Nacional de Estadística (INE), el Servicio Público de Empleo estatal (SEPE) y del Instituto de Política Familiar (IPFE).

En primer lugar y respecto del ciclo de vida de la mujer, figura 1, se ha retrasado la edad de matrimonio a los 33 años y del primer hijo a los 30,9.

Por otro lado, es interesante comprobar que las mujeres estudian más. En Europa un 34,5\% tienen educación superior frente al 30,1 \% de los hombres. En España llega al 39,8\% para las mujeres frente al 34,6 de los hombres. Están por tanto mejor formadas, y esto puede ser uno de los factores que ha repercutido en su contratación, según se puede comprobar en la imagen 2. Según los datos del SEPE a partir de Bachillerato son más las mujeres con- 
tratadas, siendo la diferencia considerablemente mayor cuando hablamos de estudios universitarios.

\section{IMAGEN 1:CICLO DE VIDA}

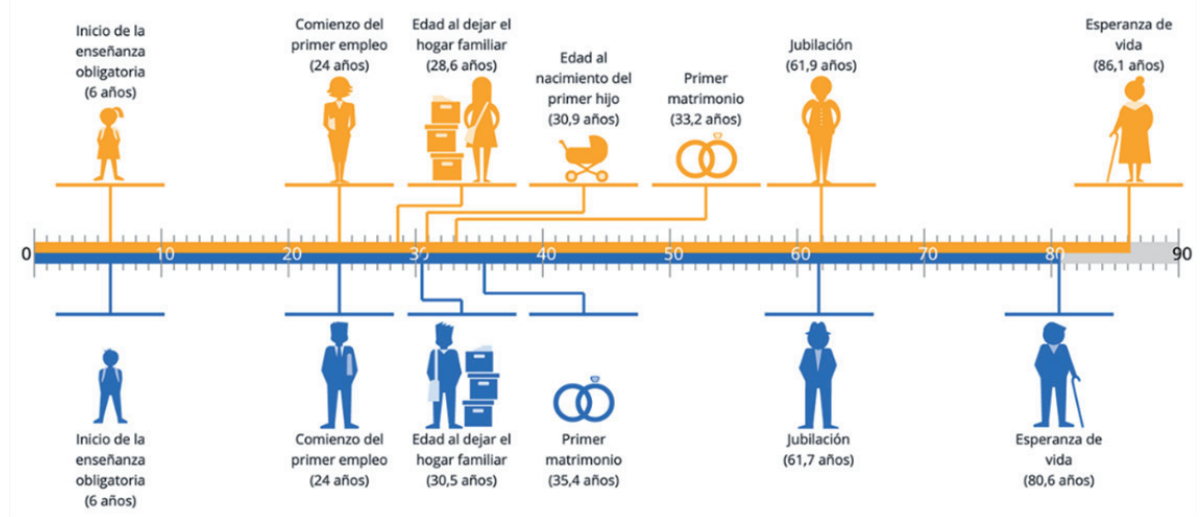

Fuente: $\quad$ INE

\section{IMAGEN 2: CONTRATACIÓN POR NIVEL FORMATIVO Y SEXO}

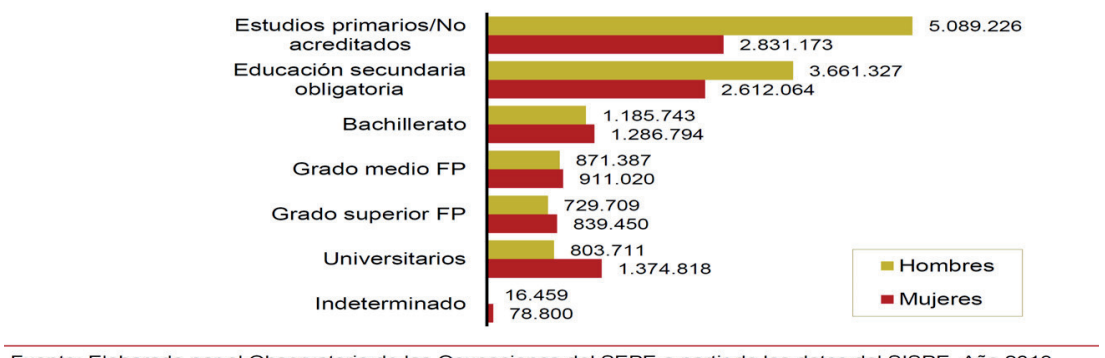

Fuente: Elaborado por el Observatorio de las Ocupaciones del SEPE a partir de los datos del SISPE. Año 2018.

Por otro lado, también hay diferencias en las actividades económicas que desarrollan las mujeres frente a los hombres. En esta línea se podrían detectar, o bien las preferencias de las mujeres a la hora de optar a distintos puestos de trabajo, o que sus cualidades hacen que sean más requeridas para ciertos puestos. 
IMAGEN 3: ACTIVIDADES ECONÓMICAS MÁS RELEVANTES EN LA CONTRATACIÓN FEMENINA

\begin{tabular}{|c|c|c|c|}
\hline Actividades económicas ${ }^{1}$ & Contratos & $\begin{array}{l}\text { Tasa mujeres } \\
(\%)\end{array}$ & $\begin{array}{l}\text { \% variación } \\
2018 / 17\end{array}$ \\
\hline Servicios de comidas y bebidas & 1.674 .932 & 51,32 & 5,97 \\
\hline Servicios de alojamiento & 631.013 & 57,98 & 3,51 \\
\hline Educación & 458.515 & 66,11 & 8,23 \\
\hline Actividades sanitarias & 426.703 & 72,89 & 4,42 \\
\hline $\begin{array}{l}\text { Actividades administrativas de oficina y otras actividades auxiliares } \\
\text { a las empresas }\end{array}$ & 360.557 & 53,17 & 4,34 \\
\hline Actividades de servicios sociales sin alojamiento & 279.122 & 79,40 & 14,26 \\
\hline $\begin{array}{l}\text { Actividades de los hogares como empleadores de personal } \\
\text { doméstico }\end{array}$ & 204.604 & 87,74 & $-0,41$ \\
\hline Otros servicios personales & 155.868 & 69,16 & $-4,65$ \\
\hline Publicidad y estudios de mercado & 135.844 & 63,12 & $-2,73$ \\
\hline Actividades relacionadas con el empleo & 116.983 & 45,22 & $-4,42$ \\
\hline
\end{tabular}

Fuente: Elaborado por el Observatorio de las Ocupaciones del SEPE a partir de los datos del SISPE. Año 2018.

$1 \mathrm{Se}$ han seleccionado las quince primeras actividades económicas, que superando la tasa estatal de contratación femenina $(44,56 \%)$, presentan mayor número de contratos suscritos por mujeres.

Nota: Se puede consultar información adicional sobre actividades económicas en: Actividades económicas con tendencia nositiva en la contratación.

Observando las cifras proporcionadas por el SEPE (2018), cabe destacar una mayor ocupación de las mujeres en trabajos relacionados con el cuidado de las personas. Los datos del año 2018, imagen 3, nos hablan de un 72,89\% como la tasa de mujeres que se ocupa en actividades sanitarias, frente por tanto al $27,11 \%$ que serían hombres. Del mismo modo un $84,22 \%$ de los empleos que cubren la asistencia en residencias estaría cubierto por mujeres, lo mismo que un $79,40 \%$ si hablamos de servicios sociales, un $87,74 \%$ en actividades del hogar, o un $66,11 \%$ en educación.

Parte de estas cifras nos hablan de las actitudes o posibles preferencias de las mujeres, como ya se ha indicado. En esta misma línea, las cifras muestran que un mayor porcentaje de mujeres se ocupa del cuidado y educación 
diaria de los hijos, como se puede observar en la imagen 4 (INE, 2018). Estas cifras corresponden al 2016, no al 2018 cuando se publican, pero se consideran comparables. En este caso, las cifras publicadas por el INE y basadas en datos de Eurofont, nos señalan cómo para Europa el 92\% de las mujeres se encargan del cuidado y educación diaria de sus hijos frente al $68 \%$ de los hombres. Para el caso español las cifras son algo superiores, el porcentaje de las madres llega al 95\%, y se mantiene la cifra media en el caso de los hombres en el $68 \%$.

IMAGEN 4: CUIDADO Y EDUCACIÓN DIARIA DE HIJOS. (\% DE ADULTOS 25-49 AÑOS)

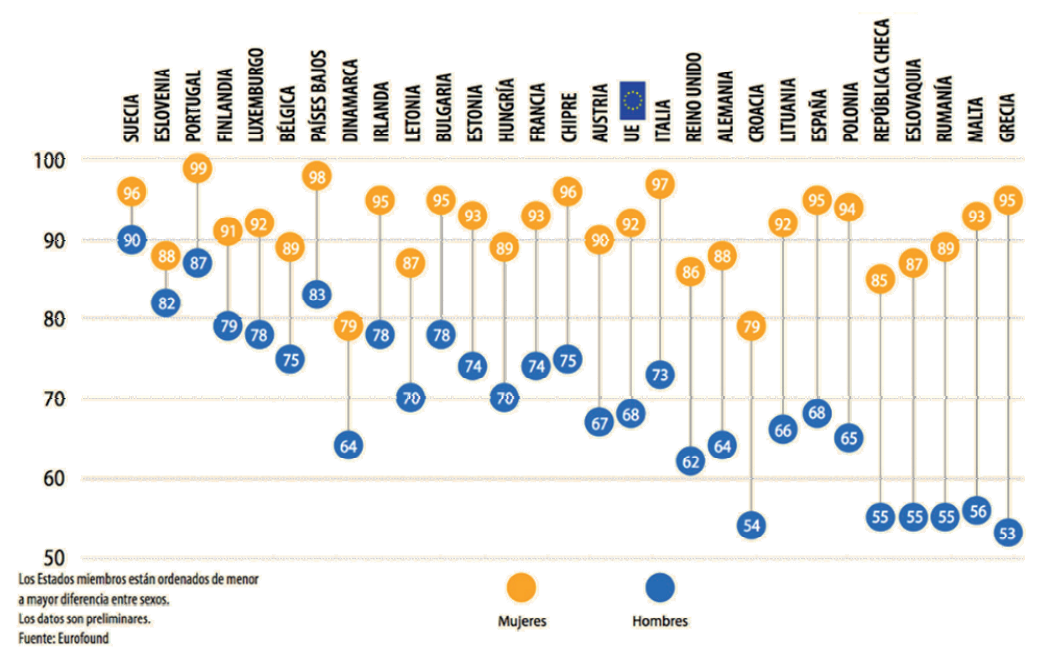

Fuente INE (2018)

Si el 95\% de las mujeres se encarga de la educación diaria de los hijos, y ciertamente este cuidado requiere tiempo, no es de extrañar que un mayor porcentaje de mujeres que de hombres tenga jornada reducida. Según el SEPE (2018) prácticamente el $21 \%$ en las mujeres frente al $14 \%$ en los hombres tiene jornada parcial. Y de la misma manera es mayor el porcentaje de mujeres que no se encuentra en el mercado laboral, un 58,24\%. 
IMAGEN 5: DISTRIBUCIÓN PORCENTUAL DE LA CONTRATACIÓN POR JORNADA LABORAL Y SEXO. EVOLUCIÓN

\begin{tabular}{r|rr|c|c|}
2018 & 41,29 & 14,14 & 23,68 & 20,89 \\
\cline { 2 - 5 } 2017 & 41,74 & 14,40 & 23,27 & 20,60 \\
\hline 2016 & 41,49 & 14,66 & 23,08 & 20,77 \\
\hline 2015 & 41,78 & 14,69 & 23,14 & 20,38 \\
\hline 2014 & 41,75 & 14,63 & 23,33 & 20,29 \\
\hline 2013 & 41,08 & 14,43 & 23,96 & 20,54 \\
\hline 2012 & 39,89 & 13,04 & 25,61 & 21,46 \\
2011 & 42,98 & 11,70 & 26,71 & 18,61 \\
2010 & 43,49 & 10,76 & 27,63 & 18,12 \\
\hline 2009 & 43,33 & 9,75 & 29,11 & 17,80 \\
\hline 2008 & 44,64 & 8,34 & 30,40 & 16,62 \\
2007 & 46,35 & 7,74 & 30,24 & 15,67 \\
\hline
\end{tabular}

Fuente: Elaborado por el Observatorio de las Ocupaciones del SEPE a partir de los datos del SISPE. Años 2007-2018. Nota: No se incluyen los contratos realizados a fijos discontinuos, en los que no consta la jornada laboral.

Por otra parte, se puede observar una tendencia creciente desde el 2007 al 2018 del porcentaje, tanto de hombres y mujeres, con contratos en jornada parcial. El incremento en caso de los hombres, de 6,4 puntos porcentuales frente a un incremento de 5,22 puntos en el caso de las mujeres, llama la atención.

Si queremos profundizar en aspectos relacionados con las familias y hogares, el IPFE (2019), nos dice que 2,5 millones de mujeres han tenido menos hijos de los deseados, 1 de cada 5 mujeres, por razones económicas y 1 de cada 4 por razones de conciliación laboral y familiar. Siendo que 4 de cada 10 parejas no tienen hijos. Dato que también se podría tener en cuenta. Este informe denuncia la falta de protección y de ayudas a las familias, en estos y otros aspectos, y en particular el caso de España frente a otros países de la UE.

También los puestos directivos, indudablemente, requieren más implicación laboral y menos tiempo para la familia. La baja representación de la mujer en este aspecto es, en Europa, de un 34\% frente al 66\% de hombres, y para el caso de España, la cifra se reduce al 31\% para las mujeres. En concreto y citando a Bel Bravo (2020, p.81) 
"Lo que a mi juicio oculta y tergiversa la teoría de la discriminación son dos cosas: la primera -es la que nos interesa a los historiadores- es que las mujeres han comenzado las carreras profesionales y, por lo tanto, la competición de las posiciones de élite mucho más tarde que los varones, por ello no se puede atribuir a una discriminación actual lo que es fruto de una discriminación del pasado, estaríamos cayendo en el más puro anacronismo. Y la segunda cuestión es que, una vez que las mujeres se han incorporado a las carreras profesionales y se puede decir que sus bases están equiparadas, ellas no han perseguido los mismos objetivos que ellos: han renunciado al ascenso por múltiples y variadas razones. Sencillamente, han escogido entre la vía matrimonial y la profesional porque, a día de hoy, eso nadie lo puede negar, sigue siendo difícil compatibilizarlas".

También en España más mujeres se ocupan diariamente del cuidado de los hijos que en Europa, tres puntos porcentuales de diferencia, la misma diferencia que en el porcentaje de directivos.

A pesar de esta baja representación de la mujer en estas áreas, no parece afectar a la satisfacción de la mayoría. El informe del INE (2018) llega a la conclusión de que, aunque hay grandes diferencias en las vidas de hombres y mujeres, en general ambos están igualmente satisfechos. Se obtiene una valoración de un 7,3 en la UE y en España.

Finalmente recordemos que, a nivel macroeconómico, si pensamos en el largo plazo para que un país se desarrolle, aparece como factor clave la inversión en educación (además de en tecnología, infraestructura o factores de ahorro) $\mathrm{Y}$ en esto, es en las familias dónde la educación juega un papel muy importante, y en esa educación cuentan el hombre y la mujer. ¿Hay un coste en el tiempo que no se pasa con los hijos y que repercute en su educación y formación? ¿Estamos renunciando al desarrollo futuro por bienes inmediatos? Son algunas preguntas que se podrían plantear a raíz de los cambios que se están produciendo. En la sociedad actual se tiende a valorar el corto plazo frente al largo. Sirva la siguiente cita para suscitar la reflexión:

"Uno de los argumentos que se exponen para que todas las mujeres estén en la población activa es que para desarrollar su economía las sociedades necesitan tomar ventaja de los talentos de todos los ciudadanos. Las madres a tiempo completo encuentran insultante este tipo de argumento. $\mathrm{La}$ clara implicación es que las mujeres que trabajan dentro del hogar están perdiendo sus talentos y su formación. Hacer un ser humano es el trabajo 
más importante de la sociedad y dedicar los propios talentos y energías a esa tarea debe considerarse tan productivo como trabajar en una fábrica o una oficina." O'Leary (2007, p.75)

Hablamos del papel de la mujer en la sociedad, de su contribución a la misma. Se habla del liderazgo femenino, pero ¿Cuál es el verdadero liderazgo?

“¿Cómo me recordarán cuando me vaya? ¿Habré dejado un legado? Son las preguntas obligadas, y a ellas responde la voz de Humberto Ak'bal que confirma que ello no depende del cargo o la posición que se ocupa en la sociedad o el trabajo, sino de lo que se es como persona y de la influencia que se haya ejercido en la vida de los demás.

"Los años han pasado, a mi madre le cansan los caminos, su voz es más pausada y su mirada divaga, tal vez, en sus recuerdos. Le cuento de mis cosas, de mis viajes. Le leo mis poemas, le canto mis cantos y ella los aprueba con un leve movimiento de su cabeza. Muchos creen que ella se siente orgullosa de tener un escritor en casa, pero no es así, para ella yo sólo soy su hijo, el poeta no cuenta, el poeta es para los demás. Ella se siente orgullosa de haber hecho de mí un hombre y me sigue viendo como si yo aún no tuviera canas.

Su voz ha quedado grabada en las ollas viejas, en la piedra de moler, en la puerta de la cocina, en el recuerdo ... Mi madre nunca escribió un libro. Ella escribió en mí, en mi sangre; yo soy su libro" DE DONIS, P. (2007, p.21)

Ciertamente el papel en la formación de las personas es trascendental, para evidenciarlo, hemos realizado una encuesta cuyos resultados corroboran nuestra afirmación de que la mujer es una pieza clave.

\section{LA MUJER EN LA ECONOMÍA DEL HOGAR: CASO DE ESTUDIO}

Para completar la investigación que se presenta en este artículo, se ha utilizado el método empírico-analítico a través de la utilización de la técnica cuantitativa de la encuesta. Las preguntas estaban dirigidas a valorar la gestión del hogar por parte de los distintos miembros. En el anexo se puede encontrar una copia de esta.

Los datos han sido recogidos durante el mes de agosto y septiembre del 2020. El medio empleado ha sido teléfono (WhatsApp), internet y redes sociales, y se ha dirigido al público en general. Se ha utilizado principalmen- 
te el muestreo no probabilístico por conveniencia (WhatsApp) y de bola de nieve, por lo que la encuesta ha sido respondida por un porcentaje alto de personas que actualmente viven en la comunidad de Castilla y León, lugar de origen de esta investigación.

La muestra final está formada por 140 personas de edades comprendidas entre los 18 y 81 . Esta amplitud de edades nos permite valorar varias generaciones, pues no solo se ha preguntado por el hogar actual sino también por el hogar de origen.

Las preguntas estaban enfocadas a valorar el papel en la gestión del hogar. Se ha preguntado desde qué miembros del hogar trabajan fuera o dentro, quien decide sobre los gastos, influencia y dedicación a los hijos, entre otros aspectos que se pasan a analizar en este apartado y que buscan un mejor conocimiento de la realidad familiar y el papel de la mujer en la misma.

En relación con las variables demográficas de la muestra, hay que señalar que ha sido contestada por un volumen mayor de mujeres 102 , un $73 \%$ frente al $27 \%$ de hombres. En relación con el lugar de nacimiento el 52\% han nacido en Castilla y León, seguido por Madrid en un 15\%, según se puede ver en la tabla 1.

Hay que señalar que la media de hermanos es de 2,7 frente a la media de hijos que resulta de 0,8 . El $57 \%$ de los encuestados no tiene hijos, siendo solo el 13,67\% menor de 26 años, o el 22\% los que viven en el mismo hogar en que nacieron. Estos datos cuadran con las cifras que presentábamos anteriormente del retraso a la hora de independizarse, en la edad de tener hijos y que se tienen menos.

Respecto de las funciones que se asumen en el hogar, cabe destacar que difieren las respuestas en función del hogar en que se ha nacido con el que se ha formado, teniendo en cuenta que el $22 \%$ siguen viviendo en el hogar en que nacieron, y por tanto no han dado respuesta al segundo bloque.

En general si comparamos los resultados vemos una evolución en las funciones asumidas. Si hablamos del hogar en que se ha crecido hay una clara diferencia entre quien trabajaba en el hogar y fuera de él, y también en el papel desarrollado dentro de la economía familiar, siendo la mujer la persona clave dentro de la economía familiar, como se puede ver en la gráfica 1. 


\begin{tabular}{|c|c|c|}
\hline Lugar de nacimiento & $\begin{array}{c}\text { Fre- } \\
\text { cuencia }\end{array}$ & $\%$ \\
\hline Andalucía & 7 & 5 \\
\hline Aragón & 2 & 1,4 \\
\hline Asturias & 2 & 1,4 \\
\hline Castilla - La Mancha & 5 & 3,6 \\
\hline Castilla y León & 73 & 52 \\
\hline Comunidad Valenciana & 1 & 0,7 \\
\hline En un país diferente a & 5 & 3,6 \\
\hline Extremadura & 7 & 5 \\
\hline
\end{tabular}

\begin{tabular}{|l|r|r|}
\hline $\begin{array}{l}\text { Lugar de } \\
\text { nacimiento }\end{array}$ & $\begin{array}{c}\text { Fre- } \\
\text { cuencia }\end{array}$ & $\%$ \\
\hline Galicia & 6 & 4,3 \\
Islas Baleares & 1 & 0,7 \\
Islas Canarias & 1 & 0,7 \\
Madrid & 21 & 15 \\
Murcia & 3 & 2,1 \\
Navarra & 4 & 2,9 \\
País Vasco & 2 & 1,4 \\
Total & 140 & 100 \\
\hline
\end{tabular}

\section{$\mathbf{N}^{0}$ de hermanos contándose con usted}

\begin{tabular}{l}
\hline $\mathbf{N}^{\mathbf{0}}$ de hijos \\
\begin{tabular}{|r|r|r|}
\hline & Frecuencia & $\%$ \\
\hline 0 & 80 & 57,1 \\
1 & 18 & 12,9 \\
2 & 27 & 19,3 \\
3 & 13 & 9,3 \\
5 & 1 & 0,7 \\
Total & $\mathbf{1 3 9}$ & $\mathbf{9 9 , 3}$ \\
\hline
\end{tabular}
\end{tabular}

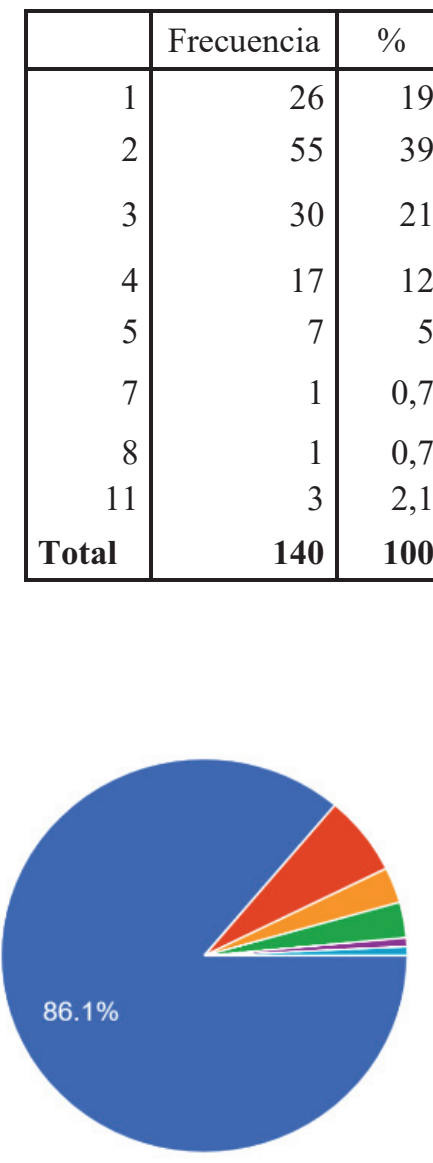

Grupos por fecha de nacimiento

\begin{tabular}{|c|r|c|}
\hline Generación & Frecuencia & $\%$ \\
\hline $1939-68$ & 21 & $15,11 \%$ \\
$1969-80$ & 38 & $27,34 \%$ \\
$1981-93$ & 61 & $43,88 \%$ \\
$1994-2002$ & 19 & $13,67 \%$ \\
\hline
\end{tabular}

Universitarios

Formación profesional

Secundaria

Primaria

Bachillerato

Bachillerato 


\section{GRÁFICA 1. EN RELACIÓN CON HOGAR EN QUE NACIÓ Y CRECIÓ}

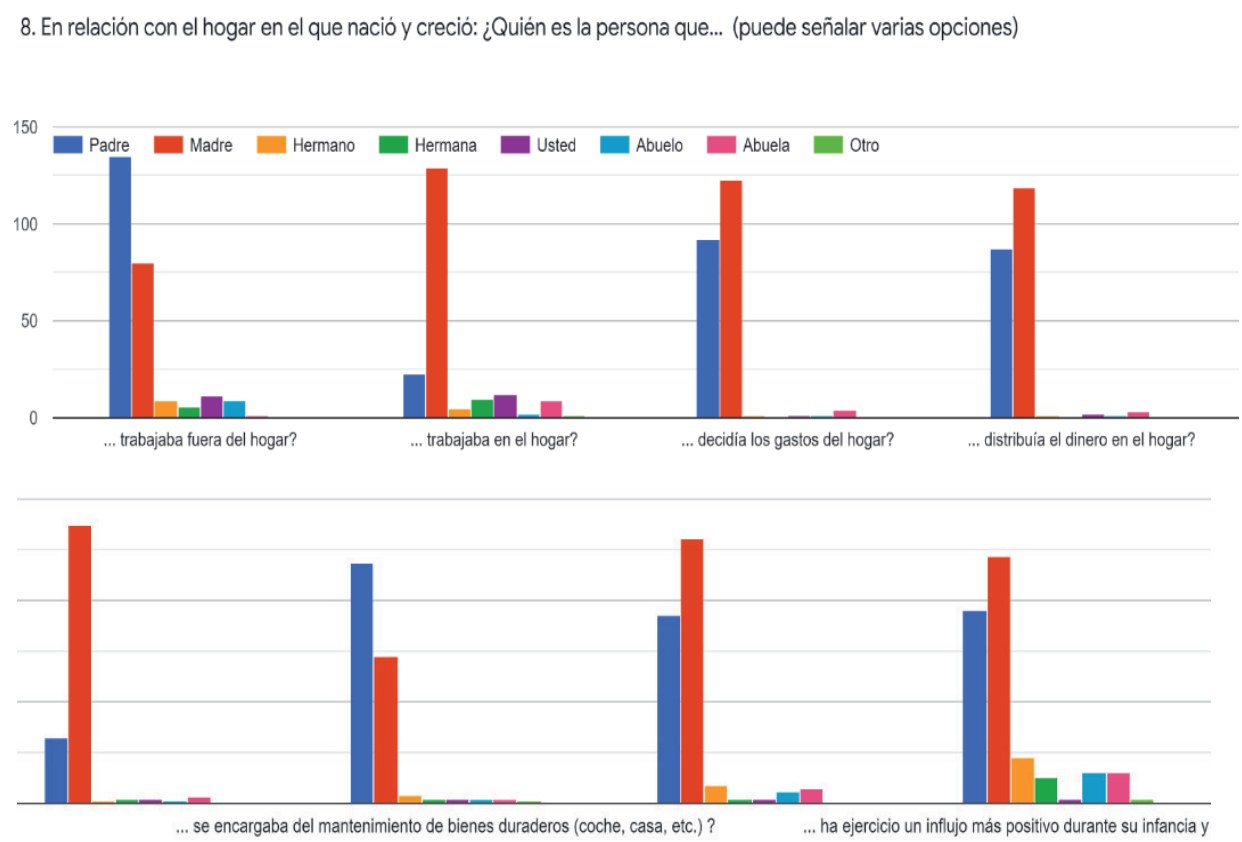

Fuente: Elaboración propia.

Nota: Las preguntas para cada uno de los ítems se encuentran en el anexo, dentro de la encuesta que allí se muestra.

Si analizamos ahora las respuestas dadas sobre las mismas preguntas, pero con relación al hogar formado, se ve una clara evolución, en dónde ya son ambos, el hombre y la mujer los que trabajan fuera, pero también dentro del hogar, y las funciones dentro del hogar pasan a estar más repartidas, como se puede ver en la gráfica 2. 


\section{GRÁFICA 2. EN RELACIÓN CON EL HOGAR QUE USTED HA FORMADO}

11. En el hogar que usted ha formado: ¿Quién es la persona que... (puede señalar varias opciones)
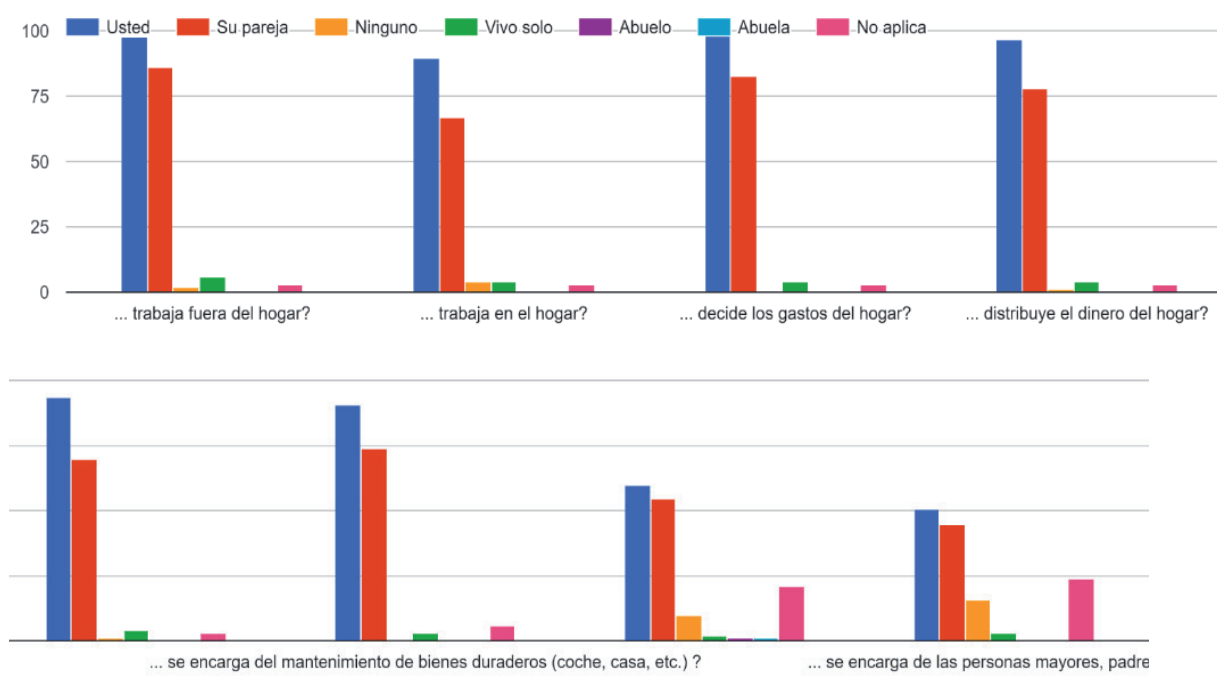

Fuente: Elaboración propia.

Nota: Las preguntas para cada uno de los ítems se encuentran en el anexo, dentro de la encuesta que allí se muestra. El usted de la pregunta se refiere tanto a hombre como a mujer.

Respecto de las valoraciones que se hacen del hogar de nacimiento y el formado, son muy similares, como se puede comprobar en la tabla 2. Siendo la valoración en general de buena, o de 4 sobre 5 . Hay cierta variación en la administración del hogar que pierde calidad, pasando del 4,45 al 4,21. 
TABLA 2: VALORACIÓN DEL HOGAR

9. ¿Cómo valoraría la organización del hogar en que nació y creció?

\begin{tabular}{|c|c|c|c|c|c|c|c|c|c|c|}
\hline & $\begin{array}{r}\text { [En to } \\
\text { gener } \\
\text { admin } \\
\text { del } 1\end{array}$ & $\begin{array}{l}\text { ninos } \\
\text { es, la } \\
\text { ación } \\
\text { ar] }\end{array}$ & $\begin{array}{r}\text { [Vida } \\
\text { familia } \\
\text { conviven } \\
\text { Tiempo } \\
\text { podían p } \\
\text { juntos }\end{array}$ & $\begin{array}{l}\text { le } \\
\text { y } \\
\text { cia. } \\
\text { que } \\
\text { sar } \\
\text { ] }\end{array}$ & $\begin{array}{r}\text { [Nive } \\
\text { vid }\end{array}$ & & $\begin{array}{l}\text { [Alin } \\
\text { ción } \\
\text { brada }\end{array}$ & $\begin{array}{l}\text { nta- } \\
\text { uili- } \\
\text { sa- }\end{array}$ & & $\begin{array}{l}\text { eso } \\
\text { ios] }\end{array}$ \\
\hline & 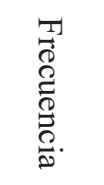 & $\%$ & $\begin{array}{l}\text { T. } \\
\overrightarrow{0} \\
\stackrel{0}{0} \\
\stackrel{0}{0} \\
\stackrel{0}{2} .\end{array}$ & $\%$ & $\begin{array}{l}\text { T. } \\
\stackrel{0}{0} \\
\stackrel{0}{0} \\
\stackrel{0}{0} \\
\text {. }\end{array}$ & $a^{\circ}$ & $\begin{array}{l}\text { T. } \\
\mathbb{0} \\
\stackrel{0}{0} \\
\stackrel{0}{0} \\
0 .\end{array}$ & $\partial^{\circ}$ & 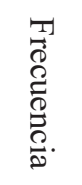 & $d^{\circ}$ \\
\hline & & & & & 1 & 0,7 & 2 & 1,4 & & \\
\hline $\begin{array}{l}\text { Buena } \\
\text { (4) }\end{array}$ & 47 & 34 & 51 & 36 & 59 & 42 & 52 & 37,1 & 39 & 27,9 \\
\hline $\begin{array}{l}\text { Excelente } \\
\text { (5) }\end{array}$ & 80 & 57 & 62 & 44 & 43 & 31 & 59 & 42,1 & 88 & 62,9 \\
\hline Mala (1) & 0 & 0 & 7 & 5 & & & 1 & 0,7 & & \\
\hline $\begin{array}{l}\text { Normal } \\
\text { (3) }\end{array}$ & 9 & 6,4 & 17 & 12 & 33 & 24 & 23 & 16,4 & 12 & 8,6 \\
\hline $\begin{array}{l}\text { Regular } \\
\text { (2) }\end{array}$ & 4 & 2,9 & 3 & 2,1 & 4 & 2,9 & 3 & 2,1 & 1 & 0,7 \\
\hline Total & 140 & 100 & 140 & 100 & 140 & 100 & 140 & 100 & 140 & 100 \\
\hline Media & 4,45 & & 4,13 & & 3,98 & & 4,14 & & $\mathbf{4 , 5 3}$ & \\
\hline
\end{tabular}


12. ¿Cómo valoraría la organización del hogar que ha formado?

\begin{tabular}{|c|c|c|c|c|c|c|c|c|c|c|}
\hline & \multicolumn{2}{|c|}{$\begin{array}{l}\text { [En términos } \\
\text { generales, la } \\
\text { administración } \\
\text { del hogar] }\end{array}$} & \multicolumn{2}{|c|}{$\begin{array}{c}\text { [Vida de } \\
\text { familia y } \\
\text { convivencia. } \\
\text { Tiempo que } \\
\text { podían pa- } \\
\text { sar juntos.] }\end{array}$} & \multicolumn{2}{|c|}{$\begin{array}{c}\text { [Nivel de } \\
\text { vida] }\end{array}$} & \multicolumn{2}{|c|}{$\begin{array}{l}\text { [Alimenta- } \\
\text { ción equili- } \\
\text { brada y sana] }\end{array}$} & \multicolumn{2}{|c|}{$\begin{array}{r}\text { [Acceso } \\
\text { estudios] }\end{array}$} \\
\hline & $\begin{array}{l}T \\
\overrightarrow{0} \\
\stackrel{0}{0} \\
\stackrel{0}{0} \\
\stackrel{0}{0} \\
.\end{array}$ & $\%$ & $\begin{array}{l}\text { T. } \\
\stackrel{0}{0} \\
\stackrel{0}{0} \\
\stackrel{0}{0} \\
\stackrel{2}{2} .\end{array}$ & $\%$ & 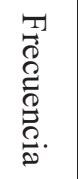 & $\%$ & $\begin{array}{l}T \\
\overrightarrow{0} \\
\stackrel{0}{0} \\
\stackrel{0}{0} \\
\stackrel{2}{2} .\end{array}$ & $\%$ & $\begin{array}{l}T \\
\overrightarrow{0} \\
\stackrel{0}{0} \\
0 \\
0 \\
\stackrel{0}{0}\end{array}$ & $\%$ \\
\hline & 31 & 22 & 32 & 23 & 31 & 22 & 31 & 22 & 31 & 22 \\
\hline Buena (4) & 54 & 39 & 45 & 32 & 63 & 45 & 64 & 46 & 40 & 29 \\
\hline $\begin{array}{l}\text { Excelente } \\
(5)\end{array}$ & 38 & 27 & 42 & 30 & 24 & 17 & 30 & 21 & 52 & 37 \\
\hline Mala (1) & & & & & 1 & 0,7 & & & & \\
\hline No aplica & 2 & 1,4 & 7 & 5 & 2 & 1,4 & 2 & 1,4 & 2 & 1,4 \\
\hline $\begin{array}{l}\text { Normal } \\
(3)\end{array}$ & 15 & 11 & 13 & 9,3 & 16 & 11 & 12 & 8,6 & 9 & 6,4 \\
\hline $\begin{array}{l}\text { Regular } \\
(2)\end{array}$ & & & 1 & 0,7 & 3 & 2,1 & 1 & 0,7 & 6 & 4,3 \\
\hline Total & 140 & 100 & 140 & 100 & 140 & 100 & 140 & 100 & 140 & 100 \\
\hline Media & 4,21 & & 4,27 & & & 3,99 & 4,15 & & 4,4 & \\
\hline
\end{tabular}

De manera complementaria se ha dividido la muestra por generaciones, para hacer un estudio intergeneracional y ver los cambios producidos en la gestión del hogar. Se ha de notar que, al dividir los grupos de esta manera, nos queda una muestra mayor en aquellos que tienen entre 27 y 39 años, generación de 1981-93, siendo 61, un 43,9\% de la muestra.

Los resultados, de esta manera separados, permiten ver algunas diferencias. 
TABLA 3: HOGAR EN QUE NACIÓ Y CRECIÓ POR GENERACIONES

8. En relación con el hogar en el que nació y creció: ¿Quién es la persona que...

\begin{tabular}{|l|r|rr|r|r|r|}
\cline { 2 - 7 } \multicolumn{1}{c|}{} & \multicolumn{1}{c|}{$\begin{array}{c}\text { [... trabajaba fue- } \\
\text { ra del hogar?] }\end{array}$} & \multicolumn{4}{c|}{... trabajaba en el hogar?] } \\
\hline Generación & Padre & $\begin{array}{c}\text { Padre, } \\
\text { Madre }\end{array}$ & Abuela & Madre & $\begin{array}{r}\text { Madre, } \\
\text { Abuela }\end{array}$ & $\begin{array}{c}\text { Padre, } \\
\text { Madre }\end{array}$ \\
\hline $1939-68$ & $71 \%$ & $19 \%$ & $0 \%$ & $86 \%$ & $0 \%$ & $5 \%$ \\
$1969-80$ & $58 \%$ & $32 \%$ & $0 \%$ & $92 \%$ & $0 \%$ & $5 \%$ \\
$1981-93$ & $25 \%$ & $56 \%$ & $3 \%$ & $57 \%$ & $5 \%$ & $13 \%$ \\
$1994-2002$ & $11 \%$ & $53 \%$ & $5 \%$ & $32 \%$ & $5 \%$ & $16 \%$ \\
\hline Total & $\mathbf{5 5}$ & $\mathbf{6 0}$ & $\mathbf{3}$ & $\mathbf{9 5}$ & $\mathbf{4}$ & $\mathbf{1 4}$ \\
\hline
\end{tabular}

8. En relación con el hogar en el que nació y creció: ¿Quién es la persona que...

\begin{tabular}{|lr|r|r|r|r|r|r|}
\multicolumn{1}{c|}{} & \multicolumn{3}{c|}{$\begin{array}{c}\text {... decidía los gastos del } \\
\text { hogar?] }\end{array}$} & \multicolumn{3}{c|}{$\begin{array}{c}\text {.. distribuía el dinero en } \\
\text { el hogar?] }\end{array}$} & \multicolumn{1}{l|}{} \\
\hline Generación & Madre & Padre & $\begin{array}{r}\text { Padre, } \\
\text { Madre }\end{array}$ & Madre & Padre & $\begin{array}{r}\text { Padre, } \\
\text { Madre }\end{array}$ & Total \\
\hline $1939-68$ & $38 \%$ & $10 \%$ & $48 \%$ & $52 \%$ & $10 \%$ & $29 \%$ & 21 \\
$1969-80$ & $37 \%$ & $8 \%$ & $53 \%$ & $45 \%$ & $11 \%$ & $42 \%$ & 38 \\
$1981-93$ & $23 \%$ & $8 \%$ & $59 \%$ & $25 \%$ & $15 \%$ & $54 \%$ & 61 \\
$1994-2002$ & $26 \%$ & $11 \%$ & $63 \%$ & $37 \%$ & $11 \%$ & $53 \%$ & 19 \\
\hline Total & $\mathbf{4 1}$ & $\mathbf{1 2}$ & $\mathbf{7 8}$ & $\mathbf{5 0}$ & $\mathbf{1 8}$ & $\mathbf{6 5}$ & $\mathbf{1 4 0}$ \\
\hline
\end{tabular}




\section{En relación con el hogar en el que nació y creció: ¿Quién es la} persona que...

\begin{tabular}{|c|c|c|c|c|c|c|}
\hline \multirow[b]{2}{*}{ Generación } & \multicolumn{3}{|c|}{$\begin{array}{c}\text {.. se encargaba de las com- } \\
\text { pras frecuentes: ¿alimenta- } \\
\text { ción, ropa? }\end{array}$} & \multicolumn{3}{|c|}{$\begin{array}{l}\text {.. se encargaba del manteni- } \\
\text { miento de bienes duraderos } \\
\text { (coche, casa, etc.) }\end{array}$} \\
\hline & Madre & Padre & $\begin{array}{l}\text { Padre, } \\
\text { Madre }\end{array}$ & Madre & Padre & $\begin{array}{l}\text { Padre, } \\
\text { Madre }\end{array}$ \\
\hline $1939-68$ & $95 \%$ & $0 \%$ & $5 \%$ & $5 \%$ & $43 \%$ & $43 \%$ \\
\hline $1969-80$ & $84 \%$ & $0 \%$ & $13 \%$ & $13 \%$ & $55 \%$ & $26 \%$ \\
\hline $1981-93$ & $69 \%$ & $2 \%$ & $21 \%$ & $15 \%$ & $41 \%$ & $39 \%$ \\
\hline 1994-2002 & $58 \%$ & $11 \%$ & $32 \%$ & $11 \%$ & $47 \%$ & $37 \%$ \\
\hline Total & 105 & 3 & 26 & 105 & 3 & 26 \\
\hline
\end{tabular}

8. En relación con el hogar en el que nació y creció: ¿Quién es la persona que...

\begin{tabular}{|l|r|r|r|r|r|r|r|r|}
\hline & \multicolumn{3}{|c|}{$\begin{array}{c}\text {.. ha tenido un papel } \\
\text { clave en su educación } \\
\text { personal? }\end{array}$} & \multicolumn{3}{|c|}{$\begin{array}{c}\text { ha ejercicio un influjo más positivo du- } \\
\text { rante su infancia y adolescencia? }\end{array}$} \\
\hline Generación & Madre & Padre & $\begin{array}{c}\text { Padre, } \\
\text { Madre }\end{array}$ & Madre & Padre & $\begin{array}{r}\text { Padre, } \\
\text { Madre }\end{array}$ & $\begin{array}{r}\text { Madre, } \\
\text { Mermano }\end{array} \begin{array}{c}\text { Padre, } \\
\text { Madre, } \\
\text { Hermano, } \\
\text { Abuelos }\end{array}$ \\
\hline $1939-68$ & $24 \%$ & $10 \%$ & $\mathbf{5 7 \%}$ & $24 \%$ & $19 \%$ & $52 \%$ & $0 \%$ & $0 \%$ \\
$1969-80$ & $32 \%$ & $3 \%$ & $55 \%$ & $21 \%$ & $8 \%$ & $45 \%$ & $5 \%$ & $0 \%$ \\
$1981-93$ & $30 \%$ & $3 \%$ & $56 \%$ & $28 \%$ & $7 \%$ & $39 \%$ & $7 \%$ & $5 \%$ \\
$1994-2002$ & $\mathbf{3 2 \%}$ & $\mathbf{0 \%}$ & $42 \%$ & $21 \%$ & $\mathbf{0 \%}$ & $26 \%$ & $5 \%$ & $5 \%$ \\
\hline Total & $\mathbf{4 1}$ & $\mathbf{5}$ & $\mathbf{7 6}$ & $\mathbf{3 4}$ & $\mathbf{1 1}$ & $\mathbf{5 8}$ & $\mathbf{7}$ & $\mathbf{4}$ \\
\hline
\end{tabular}


Según se puede ver en la tabla 3, cuando se pregunta por la persona que trabaja fuera del hogar, conforme pasan los años, o las generaciones, hay una evolución creciente en la respuesta del padre y la madre, frente a solo el padre. En la primera generación en el $71 \%$ de los hogares solo trabajaba fuera del hogar el padre frente al $11 \%$ de la última. Pero al preguntar sobre quien trabaja en el hogar la evolución es distinta, pasando del $86 \%$ para la madre al $32 \%$ y crece moderadamente la proporción del padre y de la madre, del $5 \%$ al $16 \%$. Es decir, aunque la mujer ha pasado a trabajar fuera del hogar, las funciones dentro del hogar no han variado significativamente. También resalta el papel de las abuelas que aparecen en las últimas generaciones al cargo del trabajo del hogar, y en el influjo que van a ejercer en los más jóvenes.

Cuando se pregunta sobre los gastos del hogar, en general va a ser la mujer la que se va a encargar de esta economía, presentando cierta evolución en las generaciones más jóvenes. Al igual que en el caso anterior, la mujer va teniendo menos peso en la decisión de los gastos y en la distribución del dinero del hogar, pero ciertamente sigue predominando frente al hombre en la mayoría; a excepción de la gestión de los bienes duraderos del hogar, que en general ha corrido a cargo del hombre.

Respecto de la influencia en la educación personal, si bien en torno al $50 \%$ señalan a la madre y al padre, la valoración global se decanta por el papel de la madre en la formación de los hijos. Pero cabe destacar que en las últimas generaciones aparecen otras figuras como los hermanos o los abuelos, como factor clave.

Si se analizan las correlaciones entre las variables numéricas, estas nos permiten reforzar algunos de los resultados ya comentados. En primer lugar, existe una correlación negativa entre fecha de nacimiento y el número de hermanos e hijos. Es decir, los que han nacido en años posteriores tienen menos hermanos e hijos.

Existe sin embargo una correlación positiva entre el año de nacimiento y la valoración del nivel de vida del hogar, así como el acceso a los estudios, siendo mayor en las generaciones presentes.

Otros resultados que se pueden extraer del análisis de las correlaciones y que resulta interesante comentar son los siguientes. Conforme aumenta el 
número de hijos la valoración que se hace del tiempo para el ocio o descanso, en cuanto a su capacidad para elegir, desciende. También aquellos que han nacido en familias con más hermanos tienden a tener a su vez más hijos. $\mathrm{Y}$ aquellas que tienen más tiempo para la convivencia y el tiempo que pueden pasar en familia, valoran más positivamente la administración general del hogar.

\section{CONCLUSIONES}

El papel de la mujer en la sociedad y en la formación de las personas ha sido clave y continúa siéndolo. Si en el mundo de la economía, académico e investigador, presenta un sesgo frente al hombre, en la economía familiar es la mujer la que tiene la prevalencia.

Los datos reflejan que la mujer, tanto a nivel académico como profesional se sitúa en puestos relacionados con la salud y la educación. En estudios o investigación económica estos son los temas donde la mujer sobresale, al igual que en los trabajos desempeñados, como hemos comprobado en los distintos apartados. Si estos perfiles nos hablan de una preferencia por ámbitos relacionados con el cuidado y formación de las personas, esto enlaza con el papel desempeñado por la mujer en la economía familiar.

Ciertamente su papel en la gestión del hogar ha evolucionado, aunque sigue teniendo primacía, sobre todo en el influjo en los hijos y por tanto en la sociedad. Es interesante plantearse a la luz de los datos algunas reflexiones en relación con el papel de la mujer en la economía del hogar. Si bien es cierto que el padre era, en su mayoría, la persona que trabajaba fuera del hogar y era el que conseguía los recursos, es la madre la que los acababa gestionando y distribuyendo. En general es la mujer en la mayoría de los casos, la que gestiona el hogar y por tanto las rentas de las familias. Porque, aunque los hombres se tienen a encargar de los gastos en bienes duraderos y las mujeres en los gastos más corrientes, finalmente es la mujer quien distribuye el dinero para que luego sea empleado en la adquisición y mantenimiento de los distintos bienes o servicios. Es así como, ante la pregunta de quién es quién distribuye el dinero en el hogar, 50 personas indican que solo 
la madre, 18 solo el padre, y 65 padre y madre, es decir en 115 casos aparece la madre, frente a 83 del padre. Es evidente que ha habido una evolución con el tiempo en este aspecto, pasando a compartir ambos la responsabilidad en la economía del hogar.

Por otro lado, y en relación con el influjo de los distintos miembros del hogar en la formación de los hijos, mientras que en el pasado ha recaído en el padre y la madre principalmente, o en la madre en segundo lugar, en la actualidad ha caído significativamente la valoración conjunta del padre y la madre, manteniéndose o aumentando la madre, desapareciendo la figura del padre de forma aislada y apareciendo otras figuras como los hermanos y abuelos. En este sentido se constata una pérdida de influencia del padre en las generaciones presentes. Esto llevaría a una reflexión importante. Al asumir la mujer otros papeles, su influjo se mantiene en la formación de los hijos, pero cae el influjo general de la familia. El grueso padre y madre se ven afectados negativamente en la formación de los hijos, siendo en concreto el padre el más perjudicado. Esta conclusión es importante, si se valora el papel de ambos en la formación personal y desarrollo integral de la persona, y, siendo así que la formación de las personas es clave a nivel macroeconómico en el desarrollo de un país, esto podría tener consecuencias negativas a medio plazo.

Este dato también contrasta con el hecho de que según el INE (imagen 4), el $68 \%$ de los padres contestan que se ocupan de la educación de los hijos, y sin embargo su influencia está cayendo. ¿Juega entonces la madre, en la economía familiar un papel unificador y estabilizador? Según consta en la encuesta, ¿por qué si el hombre dedica más tiempo a los hijos que antes su influencia está cayendo?

Por otra parte, las mujeres, según el IPFE, han tenido menos hijos de los deseados, y entre las razones se encuentran los motivos económicos, o de conciliación familiar. Este informe, según comentábamos, denuncia la falta de protección y de ayudas a las familias. En particular el caso de España frente a otros países de la UE.

Las investigaciones reflejan una preocupación por reducir los sesgos entre hombres y mujeres en diversos campos. Pero la pregunta que deberíamos hacernos es si este empeño va contra la mujer y contra el hombre. Si la mu- 
jer tiene menos hijos de los que quisiera, si pasa menos tiempo con ellos de lo que quisiera, si hay un problema en la conciliación familiar, etc., se debería promover políticas que ayudaran a la realización de las mujeres, más allá de perseguir que estén en puestos de dirección o cátedras, por una supuesta "igualdad". Es importante constatar que hay diferencias, pero no tienen por qué ser malas. Una búsqueda sincera de la verdad del hombre y de la mujer debería ayudarnos a aclararlo.

Si la familia es la base de la sociedad, ¿no será acaso el gestor de dicho cimiento el que tenga un papel más importante? ¿Es acaso el trabajo remunerado fuera del hogar, o los estudios académicos, más importantes que el papel desempeñado dentro de las familias? ¿Es acaso la gestión eficiente de los recursos de las empresas más importante que la gestión eficiente de los recursos en las familias?

Si la familia, el hogar es el cimiento de la sociedad, no puede descuidarse uno para fomentar el otro. Descuidar las familias, donde se forman los profesionales del futuro para nutrir la empresa actual de más mujeres profesionales, no es sostenible. Y si la mujer tiene preferencia por el cuidado, la educación, dejémosla elegir.

Somos conscientes de lo limitado de este trabajo, pero sirva como pequeña aportación al papel de la mujer en el campo de la economía y de la sociedad. Concluyendo: si la economía doméstica se encuentra en el corazón de la economía misma, es en ella dónde la mujer tiene un papel clave.

\section{REFERENCIAS BIBLIOGRÁFICAS}

Auriol, E., Friebel, G., y Wilhelm, S. (2020). Women in European economics. Europe.

Bayer, A., y Rouse, C. E. (2016). Diversity in the economics profession: A new attack on an old problem. Journal of Economic Perspectives, 30 (4), 221-42.

Bel Bravo M. A. (2020). La mujer en la historia: Ideología y realidad o cómo convertir el destino en oportunidad, Editorial Aula Magna, McGraw Hill Interamericana de España.

Beneito, P., Boscá, J. E., Ferri, J., y García, M. (2018). Women across Subfields in Economics: Relative Performance and Beliefs. Documento de Trabajo, 06. 
Boschini, A. y A. Sjögren (2007). Is Team Formation Gender Neutral? Evidence from Coauthorship Patterns, Journal of Labor Economics, 25, 325- 365.

Santamaría, N. C. (2019). Racionalidad económica y diversidad de género. Economistas, (161), 6-9.

Ceci, S. J., Ginther, D. K., Kahn, S., Y Williams, W. M. (2014). Women in academic science: A changing landscape. Psychological Science in the Public Interest, 15(3), 75-141.

Chari, A. y P. Goldsmith-Pinkham (2017). "Gender Representation in Economics across Topics and Time: Evidence from the NBER Summer Institute.” NBER Working Paper 23953.

Cortina A.: «La mujer que sostenía el Estado de bienestar se ha extinguido» disponible en:

https://www.lavozdegalicia.es/noticia/sociedad/2008/07/29/mujer-sosteniaestado-bienestar-extinguido/0003 7020187.htm

Corsi, M., C. D’ippoliti, And G. Zacchia (2014): “Gendered careers: Women economists in Italy," Working Papers CEB 17-003, ULB -Universite Libre de Bruxelles.

De Donis, P. Liderazgo: el más común de los misterios o lo más misterioso. Guatemala: Universidad del Itsmo, 2007.

Ductor, L., Sanjeev Goyal, and Anja Prummer. (2018). "Gender \& Collaboration." Cambridge-INET Working Paper 1807.

Durán, M. A. El trabajo no remunerado en la economía global, Madrid: Fundación BBVA, 2011

Ginther, D. K., y Kahn, S. (2004). Women in economics: moving up or falling off the academic career ladder? Journal of Economic perspectives, 18(3), 193214.

Linares, I., López, I. García. El nuevo papel de la mujer en la empresa. Claves de un cambio imparable que transformará el mundo laboral. Economistas, 2019, no 161, p. 85-93.

Lundberg, S and J Stearns (2019). Women in Economics: Stalled Progress, Journal of Economic Perspectives 33(1): 3-22

May, A. M., M. G. Mcgarvey, and R. Whaples (2013): Are Disagree- ments Among Male and Female Economists Marginal at Best? A Survey of AEA Members and Their Views On Economics and Economic Policy, Contemporary Economic Policy, 32, 111-132.

Mestre-Miquel, J. M. Guillen-Palomares, J.; Caro-Blanco, F. Abuelas cuidadoras en el siglo XXI: recurso de conciliación de la vida social y familiar. Portularia, 2012, vol. 12, p. 231-238.

Navarro, Vicenç, et al. (ed.) (2004). El estado de bienestar en España. Tecnos. 
O'leary, Dale. (2007). La agenda de género: redefiniendo la igualdad. Promesa.

Rico Gonzalez, M.; Gomez Garcia, J. M. (2009). La contribución de la mujer en la economía rural de Castilla y León. Economía Agraria y Recursos Naturales;vol. 9, no 1380-2016-115382, p. 51-77.

Scott, Ch. E., y J. J. Siegfried (2016). American Economic Association Universal Academic Questionnaire Summary Statistics. American Economic Review 106 (5): 680-82

West, J. D., Jacquet, J., King, M. M., Correll, S. J., \& Bergstrom, C. T. (2013). The role of gender in scholarly authorship. PloS one, 8(7), e66212.

Instituto Nacional de Estadística. Direcciones consultadas:

https://www.ine.es/dyngs/INEbase/es/categoria.htm?c=Estadistica_P\&cid=1254 735971047

https://www.ine.es/prodyser/myhue19/bloc-2b.html?lang=es

https://www.ine.es/prodyser/myhue19/bloc-1a.html?lang=es

https://www.ine.es/prodyser/myhue19/bloc-3d.html?lang=es

Instituto de Política Familiar, disponible en:

http://www.ipfe.org/Espa\%C3\%B1a/Documentos/IPF 


\section{ANEXO}

Cuestionario realizado durante los meses de agosto y septiembre de 2020

\section{Economía familiar}

Desde la Cátedra de estudios sobre la mujer, de la Universidad católica de Ávila, se está realizando una encuesta destinada a conocer el papel de las mujeres y los hombres en la economía familiar. Agradecemos sinceramente su participación.

1. Sexo: Hombre - Mujer

2. Año de nacimiento:

3. Estudios (Universitarios, Formación profesional, Secundaria, Primaria, otros)

4. Lugar de nacimiento: Comunidad autónoma / País (desplegable)

5. Lugar de residencia: Comunidad autónoma / País (desplegable)

6. Número de hermanos contándose a usted: $0,1,2,3,4,5,6,7,8,9,10$, 11,12 , mas

7. Número de hijos, $0,1,2,3,4,5,6,7,8,9,10,11,12$, mas

8. En relación con en el hogar en el que nació y creció, (puede señalar varias opciones):

\begin{tabular}{|c|c|c|c|c|c|c|c|c|}
\hline ¿Quién es la persona que... & 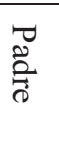 & 坣 & 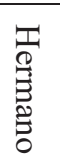 & 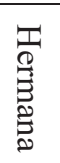 & 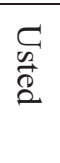 & $\begin{array}{l}\mathbb{Z} \\
\stackrel{0}{0} \\
\frac{0}{0}\end{array}$ & $\begin{array}{l}\mathbb{D} \\
\stackrel{D}{0} \\
\frac{D}{2}\end{array}$ & $\begin{array}{l}\text { O } \\
\stackrel{0}{0} \\
\&\end{array}$ \\
\hline ...trabajaba fuera del hogar? & & & & & & & & \\
\hline ...trabajaba en el hogar? & & & & & & & & \\
\hline $\begin{array}{l}\text {...ha tenido un papel clave en su } \\
\text { educación personal? }\end{array}$ & & & & & & & & \\
\hline $\begin{array}{l}\ldots . \text { ha ejercicio un influjo más positivo } \\
\text { durante su infancia y adolescencia? }\end{array}$ & & & & & & & & \\
\hline ...decide los gastos del hogar? & & & & & & & & \\
\hline ... distribuye el dinero en el hogar? & & & & & & & & \\
\hline $\begin{array}{l}\text {...se encarga de las compras frecuen- } \\
\text { tes: ¿alimentación, ropa...? }\end{array}$ & & & & & & & & \\
\hline $\begin{array}{l}\ldots \text { se encarga del mantenimiento de } \\
\text { bienes duraderos (coche, casa, etc.) }\end{array}$ & & & & & & & & \\
\hline
\end{tabular}


9. ¿Cómo valoraría la organización del hogar en que nació y creció?

\begin{tabular}{|l|l|l|l|l|l|l|}
\hline & Excelente & Buena & Normal & Regular & Mala & $\begin{array}{l}\text { No } \\
\text { sabe }\end{array}$ \\
\hline $\begin{array}{l}\text { En términos generales, la } \\
\text { administración del hogar }\end{array}$ & & & & & & \\
\hline $\begin{array}{l}\text { Vida de familia y convi- } \\
\text { vencia. Tiempo que podían } \\
\text { pasar juntos. }\end{array}$ & & & & & & \\
\hline Nivel de vida & & & & & & \\
\hline $\begin{array}{l}\text { Alimentación equilibrada y } \\
\text { sana }\end{array}$ & & & & & & \\
\hline Acceso estudios & & & & & & \\
\hline
\end{tabular}

10. ¿Vive actualmente en el mismo hogar en el que nació y creció? Si: pase a la pregunta 13, NO: pase a la pregunta 11 .

11. En el hogar que usted ha formado (puede señalar varias opciones):

\begin{tabular}{|c|c|c|c|c|c|c|c|}
\hline ¿Quién es la persona que... & 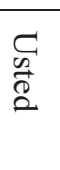 & 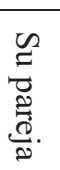 & $\begin{array}{c}\underset{5}{Z} \\
\stackrel{0}{0} \\
\stackrel{0}{0}\end{array}$ & $\begin{array}{l}\leq \\
0 \\
0 \\
\text { n } \\
0 \\
0\end{array}$ & $\begin{array}{l}\mathbb{R} \\
\stackrel{\vec{\Xi}}{0} \\
\frac{0}{0}\end{array}$ & $\begin{array}{l}\vec{D} \\
\stackrel{0}{D} \\
\frac{D}{2}\end{array}$ & $\begin{array}{l}z \\
0 \\
\text { है } \\
\text { है. }\end{array}$ \\
\hline trabaja fuera del hogar? & & & & & & & \\
\hline trabaja en el hogar? & & & & & & & \\
\hline ...decide los gastos del hogar? & & & & & & & \\
\hline .. distribuye el dinero en el hogar? & & & & & & & \\
\hline $\begin{array}{l}\text {...se encarga de las compras frecuentes: } \measuredangle \text { al } \\
\text { mentación, ropa...? }\end{array}$ & & & & & & & \\
\hline $\begin{array}{l}\text {... se encarga del mantenimiento de bienes } \\
\text { duraderos (coche, casa, etc.) }\end{array}$ & & & & & & & \\
\hline $\begin{array}{l}\text {... se encarga de los hijos, ayudar con los } \\
\text { deberes, escuchar, educar? }\end{array}$ & & & & & & & \\
\hline $\begin{array}{l}\text {... se encarga de las personas mayores, pa- } \\
\text { dres, etc.? }\end{array}$ & & & & & & & \\
\hline
\end{tabular}


12. Cómo valoraría la organización del hogar que ha formado

\begin{tabular}{|c|c|c|c|c|c|c|}
\hline & 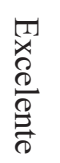 & $\underset{\overparen{D}}{\varpi}$ & 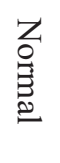 & 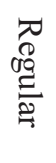 & 党 & 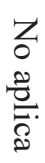 \\
\hline $\begin{array}{l}\text { En términos generales, la admini } \\
\text { hogar }\end{array}$ & & & & & & \\
\hline $\begin{array}{l}\text { Vida de familia y convivencia. } \mathrm{T} \\
\text { san juntos. }\end{array}$ & & & & & & \\
\hline Nivel de vida & & & & & & \\
\hline Alimentación equilibrada y sana & & & & & & \\
\hline Acceso estudios & & & & & & \\
\hline
\end{tabular}

13. Capacidad de elección. Valore, donde 5 es muy satisfecho, y 0 nada satisfecho

\begin{tabular}{|l|l|l|l|l|l|l|l|}
\hline & 5 & 4 & 3 & 2 & 1 & 0 & $\begin{array}{l}\text { No apli- } \\
\text { ca }\end{array}$ \\
\hline Tiempo que paso con mis hijos & & & & & & & \\
\hline $\begin{array}{l}\text { Tiempo que paso atendiendo a mis } \\
\text { padres }\end{array}$ & & & & & & & \\
\hline $\begin{array}{l}\text { Posibilidad de elegir la jornada laboral, } \\
\text { completa o parcial }\end{array}$ & & & & & & & \\
\hline $\begin{array}{l}\text { Tiempo que dedico a mi preparación } \\
\text { profesional, estudios }\end{array}$ & & & & & & & \\
\hline Tiempo de ocio y descanso & & & & & & & \\
\hline
\end{tabular}

Finalmente, si desea añadir algún comentario o valoración adicional.

https://docs.google.com/forms/d/e/1FAIpQLScbtxfwLDCfitnmH16QVBoJE PMj1PA2QUpxYwx0fnmc0Ud4iA/viewform? $v c=0 \& c=0 \& w=1$ 